\title{
Synthesis of Calcium Carbonate by Semicontinuous Carbonation Method in the Presence of Dextrans
}

\author{
Jasminka Kontrec, ${ }^{*}$ Marko Ukrainczyk, Vesna Babić-Ivančić, and Damir Kralj \\ Laboratory for Precipitation Processes, Ruđer Bošković Institute, P.O. Box 180, HR-10002 Zagreb, Croatia
}

RECEIVED SEPTEMBER 3, 2010; REVISED DECEMBER 3, 2010; ACCEPTED DECEMBER 6, 2010

\begin{abstract}
Precipitated calcium carbonate (PCC) was prepared by means of semicontinuous carbonation of $\mathrm{Ca}(\mathrm{OH})_{2}$ suspension, at 35 and $45^{\circ} \mathrm{C}$ and in the presence of non-ionic dextran and dextran sulfate. The carbonation process was regulated at different predetermined values of electrical conductivity, that corresponded to different concentrations of dissolved $\mathrm{Ca}(\mathrm{OH})_{2}: 0.5 \mathrm{mS} \mathrm{cm}{ }^{-1}<\kappa_{25}<5.0 \mathrm{mS} \mathrm{cm}^{-1}$. The results of physicalchemical characterization of the product showed that calcite was the only polymorphic modification obtained in the whole range of experimental conditions investigated. In addition, it was found that morphology, crystal size distribution and specific surface area of PCC strongly depended on the electrical conductivity / concentration of dissolved $\mathrm{Ca}(\mathrm{OH})_{2}$, at which the process was performed: predominantly scalenohedral crystals of higher surface area (about $5 \mathrm{~m}^{2} \mathrm{~g}^{-1}$ ) were produced at higher electrical conductivity, while at lower electrical conductivity predominantly rhomohedral calcite crystals of relatively low specific surface area were obtained. In the system of the highest electrical conductivity, $\kappa_{25}=5.0 \mathrm{mS} \mathrm{cm}{ }^{-1}$, and at $35^{\circ} \mathrm{C}$, the addition of non-ionic dextran significantly influenced the process by preventing the regulation. The crystals that appeared were in the form of irregular aggregates of high specific surface area, $S \approx 29 \mathrm{~m}^{2} \mathrm{~g}^{-1}$. FT-IR and TG analyses indicated that the non-ionic dextran was adsorbed onto the calcite surface, most probably by relatively strong and specific interactions between oxygen from the hydroxyl groups of dextran molecules and calcium ions from the crystal surface. On the contrary, the anionic dextran (dextran sulfate) exerted minor effects in the course of semicontinuous carbonation process and in the properties of the final product, PCC. However, the analysis of the precipitate indicated that dextran sulfate was adsorbed at the surfaces, most probably by the weak and non-specific electrostatic interactions. (doi: $10.5562 / \mathrm{cca} 1746$ )
\end{abstract}

Keywords: precipitated calcium carbonate, carbonation, polysaccharide, dextran

\section{INTRODUCTION}

Precipitated calcium carbonate is multifunctional mineral filler extensively used in the paper, paints, plastics, cosmetics, food and textile industries. The properties of the calcium carbonate required by wide applications are different. Development of methods to produce materials with desired physical-chemical properties attract great attentions in many scientific and industrial fields. One route involves mechanical treatment of minerals directly from stone-pit to create a powdery-like form of calcium carbonate which is named ground calcium carbonate, GCC. The production of precipitated calcium carbonate, PCC, includes the precipitation process in which a range of different reactant solutions are used. ${ }^{1,2}$ The precipitation of calcium carbonate may also be carried out by introducing gaseous carbon dioxide into the lime solution. ${ }^{3}$ Generally, carbonation of slaked lime in the batch process is the only commercially relevant synthetic route. ${ }^{4-8}$ Among the three polymorphic modifications of calcium carbonate (calcite, aragonite and vaterite) calcite is the most important PCC polymorph in industrial applications. It appears in various crystalline forms (scalenohedral, rhombohedral, spheroidal, etc.) but the scalenohedral form is favoured in most of applications.

The main disadvantage of the batch carbonation route is the limited possibility of controlling supersaturation of the system. By using the semicontinuous carbonation process it is possible to adjust supersaturation and to control morphology and size of the PCC. ${ }^{9,10}$ In our previous work, ${ }^{11}$ the physical-chemical properties of PCC, prepared by carbonation of slaked lime in the batch and semicontinuous processes, were compared. Other important ways to influence on the PCC particle morphology are the use of magnetic field, ${ }^{12,13}$ high pressure, ${ }^{14,15}$ or a specific additive. ${ }^{16-22}$

The paper industry uses a huge amount of calcium carbonate as a filler component. The more filler is applied, the cost of the final product is lower. In addition, PCC tends to increase the life of a paper product be-

* Author to whom correspondence should be addressed. (E-mail: jasminka.kontrec@irb.hr) 
cause the use of acid in the production process is usually avoided when PCC is employed. When PCC is incorporated into the paper matrix, it increases whiteness, brightness, and opacity. Thus, the investigations of PCC with a beneficial properties for filler-fibre composites remain a primary concern of the paper industry. ${ }^{23-27} \mathrm{~A}$ large group of organic macromolecular additives, used for optimizing the calcium carbonate properties, are water-soluble polysaccharides. ${ }^{16,17,28,29}$ These additives are important because of their structural similarities to cellulose and other wood polysaccharides. The study reported in this paper is a continuation of our work on the influence of soluble starch and non-ionic, cationic and anionic dextrans on the precipitation of calcium carbonate in the model system in which solutions of calcium hydroxide and carbonic acid were reactants. ${ }^{30}$ It was found that these additives modified the morphology and the size of the precipitated particles, as well as the composition of the precipitate. The results showed that the adsorption of anionic dextran inhibited crystal growth of PCC. Among the all additives used, calcite was found to be the predominant solid phase formed in the presence of non-ionic dextran only. It was also found ${ }^{10}$ that calcite in the form of scalenohedral crystals can be produced by a careful tuning of the semicontinuous process parameters. This morphology is mostly used as a PCC filler in paper industry.

The main goal of this work was to investigate the influence of two types of dextran, anionic and nonionic, on the precipitation of PCC by carbonation of calcium hydroxide suspension, as well as on its physical-chemical properties. The role of ionic charge and concentration of the selected polysaccharide in the process of precipitation of calcium carbonate, its crystal size and morphology were systematically investigated. The synthesis was performed under adjustable supersaturation by using a semicontinuous process.

\section{EXPERIMENTAL}

The precipitation of calcium carbonate was performed in a thermostated glass reactor of $1.6 \mathrm{dm}^{3}$ total volume capacity. The reactor was closed by a Teflon cover and was equipped with a thermometer and a conductivity cell connected to the Radiometer CDM 230 conductivity meter. The experiments were carried out at $35{ }^{\circ} \mathrm{C}$ and $45^{\circ} \mathrm{C}$. The suspension was continuously stirred at a constant rate $\left(n=400 \mathrm{~min}^{-1}\right)$ by means of a flat-bladed stirrer with the dimension being $1 / 3$ of the reactor diameter $(D)$. The stirrer was placed $D / 3$ from the bottom of the reactor. In order to improve mixing and to prevent the vortex formation during stirring, the reactor was fitted with two baffle plates of $D / 12$ in width. The propagation of the precipitation process was followed by monitoring electrical conductivity as a function of time. The experiments started by bubbling the appropriate gas mixture into the aqueous solution of dextran, until the saturation, detected as constant conductivity, was achieved. The gas mixture containing $20 \% \mathrm{CO}_{2}$ and $80 \% \mathrm{~N}_{2}$ (Messer Group $\mathrm{GmbH}$ ) simulates the flue gases that are commonly used in the technological processes for the production of precipitated calcium carbonate by carbonation route. Gas was introduced into the reactor through the baffles; at the bottom of each a nozzle of $0.7 \mathrm{~mm}$ in diameter was placed. Precipitation was initiated by a controlled addition of the thermostated $\mathrm{Ca}(\mathrm{OH})_{2}$ suspension $\left(\gamma\left(\mathrm{Ca}(\mathrm{OH})_{2}\right)=100 \mathrm{~g} \mathrm{~cm}^{-1}\right)$ into the reactor by using peristaltic pump. The electrical conductivity was monitored and kept constant at different predetermined values, in the range $0.5 \mathrm{mS} \mathrm{cm}^{-1}<$ $\kappa_{25}<5.0 \mathrm{mS} \mathrm{cm}{ }^{-1}$. This predetermined electrical conductivity was correlated with the concentration of total dissolved $\mathrm{Ca}(\mathrm{OH})_{2}, c(\mathrm{Ca})_{\text {tot }}$, determined by means of an ion chromatography system ICS-1100 (Dionex) fitted with CS16 Analytical Column. ${ }^{22}$

The flow of the $\mathrm{Ca}(\mathrm{OH})_{2}$ suspension was stopped 10 min after starting the experiment, while the gas flow was kept constant until the endpoint of carbonation reaction. This point was indicated by an abrupt drop in conductivity and its subsequent increase. At the end of each experiment, the suspension was centrifuged for 10 $\min , n_{\mathrm{c}}=4000 \mathrm{~min}^{-1}$, the precipitates were washed with small portions of water and dried at $105{ }^{\circ} \mathrm{C}$. The precipitates were analysed by Fourier transform infrared, FT-IR, spectroscopy (Mattson, FT-IR spectrophotometer, Genesis Series), thermogravimetry, TG (Mettler, TG 50 thermobalance with TC $11 \mathrm{TA}$ processor) and X-ray powder diffraction, XRD (Philips 1710 with a $\mathrm{CuK} \alpha$ radiation), while the specific surface area was determined by the multiple BET method (Micromeritics, Gemini) using nitrogen gas as adsorbate. The morphology of particles was examined by using scanning electron microscopy, SEM (Tescan TS 5136).

Two types of commercial dextrans (Polydex Chemicals Ltd.), non-ionic and anionic (dextran sulfate), were used without further purification (Figure 1). Their relative molecular masses varied in the range $6000-500000 \mathrm{~g} \mathrm{~mol}^{-1}$ and the mass concentrations varied from 60 to $6000 \mathrm{mg} \mathrm{dm}^{-3}$.

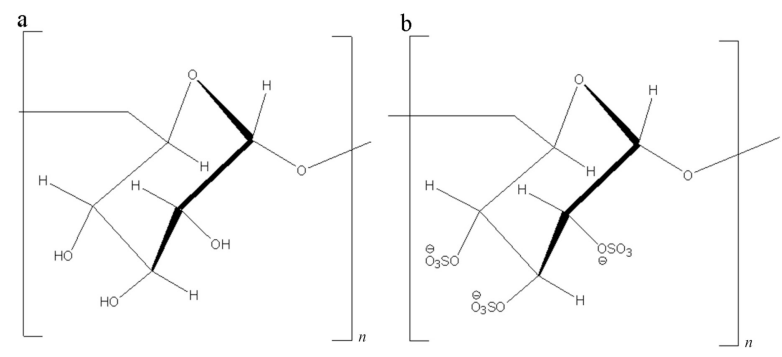

Figure 1. Dextran monomers: a) non-ionic, and b) anionic (dextran sulfate). 


\section{RESULTS AND DISCUSSION}

Since it is known that physical properties of slightly soluble salts, like calcium carbonates, principally depend on the initial supersaturation and temperature, the carbonation process of PCC preparation performed in this study was conducted at two different temperatures $\left(t=35^{\circ} \mathrm{C}\right.$ and $\left.t=45{ }^{\circ} \mathrm{C}\right)$ and at different value of the electrical conductivity that corresponded to different concentration of dissolved $\mathrm{Ca}(\mathrm{OH})_{2}$. However, a flow of the gas mixture, $Q=7.5 \mathrm{dm}^{3} \min ^{-1}$ was kept constant during the experiments. Figure 2 shows typical progress curves ( $\kappa_{25} v s$. time) recorded during the carbonation of slaked lime in a semicontinuous process. The experiments were performed at $35{ }^{\circ} \mathrm{C}$, under conditions of different predetermined value of electrical conductivity $\left(0.5 \mathrm{mS} \mathrm{cm}^{-1}<\kappa_{25}<5.0 \mathrm{mS} \mathrm{cm}^{-1}\right)$.

The initial part of each curve, seen as an abrupt increase of conductivity, corresponds to the dissolution of $\mathrm{Ca}(\mathrm{OH})_{2}$ introduced into the system. The conductivity plateaus, observed at the predetermined values, indicate the regulated part of the process attained by the addition of $\mathrm{Ca}(\mathrm{OH})_{2}$ suspension into the reactor. However, after termination of the addition of $\mathrm{Ca}(\mathrm{OH})_{2}$ suspension, the flow of the gas mixture was maintained so that the carbonation of $\mathrm{Ca}(\mathrm{OH})_{2}$ excess could be completed. Consequently, $\kappa_{25}$ rapidly decreased to the minimum value. Further bubbling of $\mathrm{CO}_{2}$ caused dissolution of the already prepared $\mathrm{PCC}$, which is observed as a final increase of $\kappa_{25}$. The XRD and FT-IR analysis indicated that calcite was the only calcium carbonate polymorph obtained under all experimental conditions.

The specific surface area is probably the most important property of PCC and strongly determines its subsequent use as filler or additive. Figure 3 shows the results of specific surface area measurements of calcite

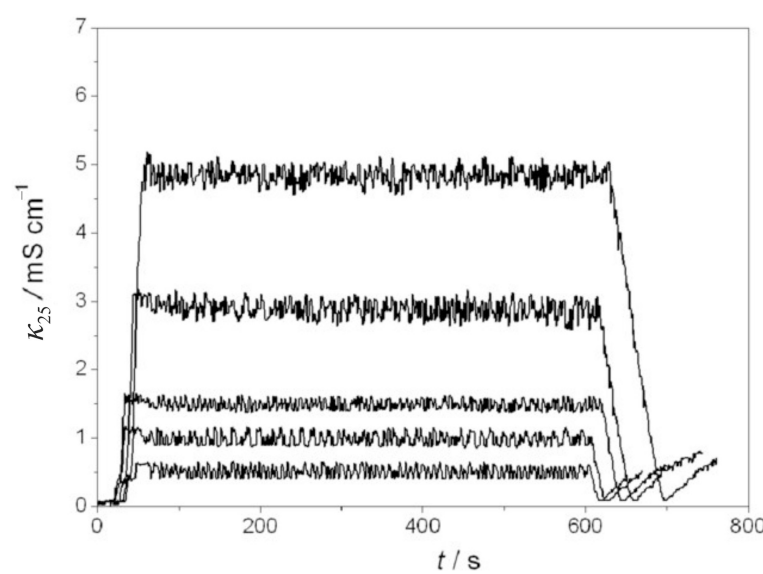

Figure 2. Progress curves, $\kappa_{25}$ versus time, of semicontinuous carbonation process performed at $35{ }^{\circ} \mathrm{C}$ and different predetermined value of electrical conductivity: $0.5 \mathrm{mS} \mathrm{cm}^{-1}<\kappa_{25}<$ $5.0 \mathrm{mS} \mathrm{cm}^{-1}$.

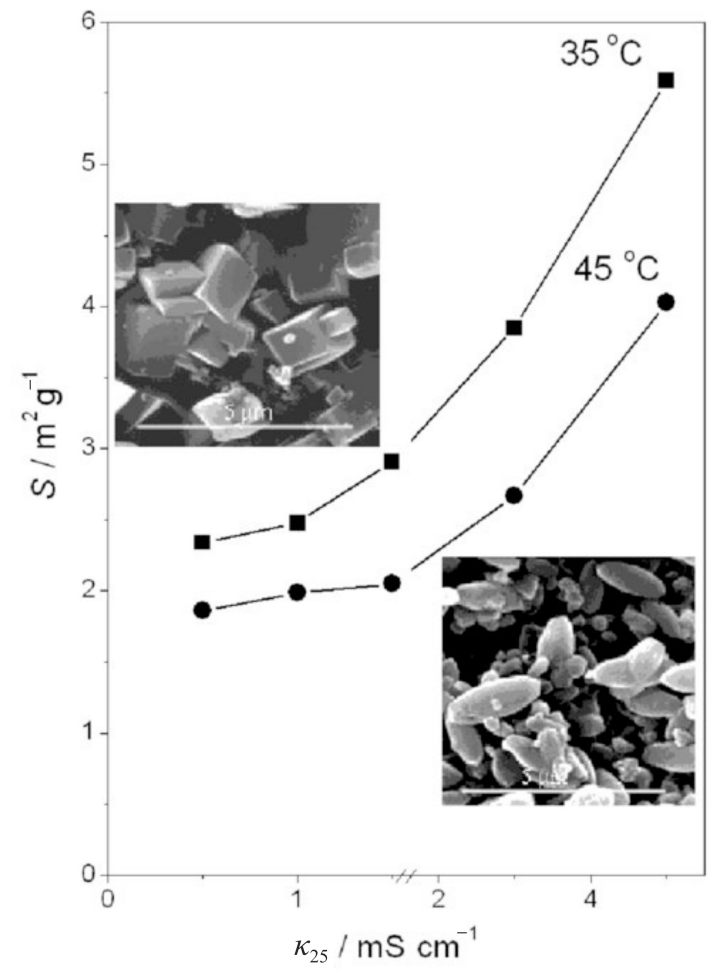

Figure 3. Specific surface area of PCC prepared by semicontinuous process at different electrical conductivity and temperatures. Typical SEM images of PCC prepared at lower and higher electrical conductivity are included.

samples prepared at different conditions. It is evident that the specific surface area of PCC, $S$, gradually increases with increasing the conductivity: the increase of $S$ at $35{ }^{\circ} \mathrm{C}$ is from about 2.3 to $5.6 \mathrm{~m}^{2} \mathrm{~g}^{-1}$, while at 45 ${ }^{\circ} \mathrm{C}$ this increase ranges from about 1.9 to $4.0 \mathrm{~m}^{2} \mathrm{~g}^{-1}$. It is also evident that at the same conductivity, the measured surface areas of calcite samples prepared at lower temperatures are higher. These findings are in accordance with the theoretical models of precipitation by which an increase of driving force for precipitation, i.e. supersaturation, determined by concentration of total dissolved calcium and carbonate, gives rise to nucleation of a larger number of smaller crystals having higher specific surface area. Therefore, the observed temperature dependence of specific surface area is a consequence of lower $\mathrm{CO}_{2}$ solubility at higher temperatures, which causes lower supersaturation.

Morphological analysis of the PCC samples obtained at $35{ }^{\circ} \mathrm{C}$ showed a gradual change of the calcite shape with changing the supersaturation: predominantly rhombohedral crystals were formed at low conductivity, $\kappa_{25} \leq 1.0 \mathrm{mS} \mathrm{cm}^{-1}$ (low calcium concentration, $c(\mathrm{Ca})_{\mathrm{tot}} \leq$ $2.4 \mathrm{mmol} \mathrm{dm}{ }^{-3}$ ), rhombo-scalenohedral crystals were formed at moderate conductivity, $\kappa_{25}>1.0 \mathrm{mS} \mathrm{cm}{ }^{-1}$ (moderate concentrations, $c(\mathrm{Ca})_{\text {tot }}>2.4 \mathrm{mmol} \mathrm{dm}^{-3}$ ), 
while predominantly scalenohedral crystals were obtained at the highest conductivity, $\kappa_{25}=5.0 \mathrm{mS} \mathrm{cm}^{-1}$ (highest concentrations, $c(\mathrm{Ca})_{\text {tot }}=12.0 \mathrm{mmol} \mathrm{dm}^{-3}$ ) investigated in this study. Similarly, at $45{ }^{\circ} \mathrm{C}$ the gradual change of morphology from rhombohedral to scalenohedral was also observed, with a slight shift in the concentration range: rhombohedral crystals precipitated at $c(\mathrm{Ca})_{\mathrm{tot}} \leq 3.6 \mathrm{mmol} \mathrm{dm}^{-3}\left(\kappa_{25} \leq 1.5 \mathrm{mS} \mathrm{cm}^{-1}\right)$, while at higher calcium concentrations, $c(\mathrm{Ca})_{\text {tot }}>3.6 \mathrm{mmol} \mathrm{dm}^{-3}$ $\left(\kappa_{25}>1.5 \mathrm{mS} \mathrm{cm} \mathrm{cm}^{-1}\right)$, the crystals of rhomboscalenohedral morphology were obtained. Figure 3 shows typical scanning electron micrographs of predominantly rhomohedral PCC and predominantly scalenohedral crystals obtained at lower and higher calcium concentrations, respectively.

It is interesting to note that a relation between the morphology of PCC crystals and their specific surface area, $S$, was also found: the specific surface area of rhombohedral calcite was found to be $S \approx 2.0 \mathrm{~m}^{2} \mathrm{~g}^{-1}$, the $S$ value of the truncated prismatic and/or rhomboscalenohedral calcite was $S \approx 3.0-6.0 \mathrm{~m}^{2} \mathrm{~g}^{-1}$ and of the scalenohedral crystals was $S \approx 7.0 \mathrm{~m}^{2} \mathrm{~g}^{-1}$ (Figure 3). Similar correlation between the morphology and the specific surface area of calcite was reported in the literature ${ }^{5,10,22}$ and for the batch carbonation process in particular, in which scalenohedral calcite is regularly produced in the absence of any additives. A likely explanation for the observed formation of stable rhombohedral $\{104\}$ calcite surfaces at lower calcium concentrations and less stable scalenohedral $\{214\}$ surfaces at higher calcium concentrations is also in accordance with the fundamental precipitation principles, that postulate the formation of metastable, precursor, solid phases or less stable morphologies at a high driving force. ${ }^{5}$ In addition to the increase of the driving force (supersaturation) the morphological change might take place also because of different $\mathrm{pH}$ of the bulk solution and the different ratios between the calcium and carbonate concentrations. Thus, it was suggested that the adsorbed $\mathrm{OH}^{-}$ions, present at higher $\mathrm{pH}$, stabilized the formation of scalenohedral surfaces, ${ }^{31}$ while the deplacement of the scalenohedral faces is inhibited by adsorption of the excess Ca species. ${ }^{5}$

The effect of non-ionic dextran on semicontinuous carbonation process of PCC production was investigated by the addition of different concentrations of the selected dextran into the respective precipitation system. However, the preliminary experiments indicated that the strongest effect of the dextrans with molecular masses ranging from 6000 to $500000 \mathrm{~g} \mathrm{~mol}^{-1}$ were obtained for $M_{\mathrm{r}}=150000 \mathrm{~g} \mathrm{~mol}^{-1}$. At that, as a criterion for the relevant estimate of the effect of dextran, the relative increase of specific surface area of the precipitate was chosen. The carbonation process in which the highest yield of product can be obtained $\left(\kappa_{25}=5.0 \mathrm{mS} \mathrm{cm}{ }^{-1}, t=35^{\circ} \mathrm{C}\right)$ was used as a representative precipitation system.
A

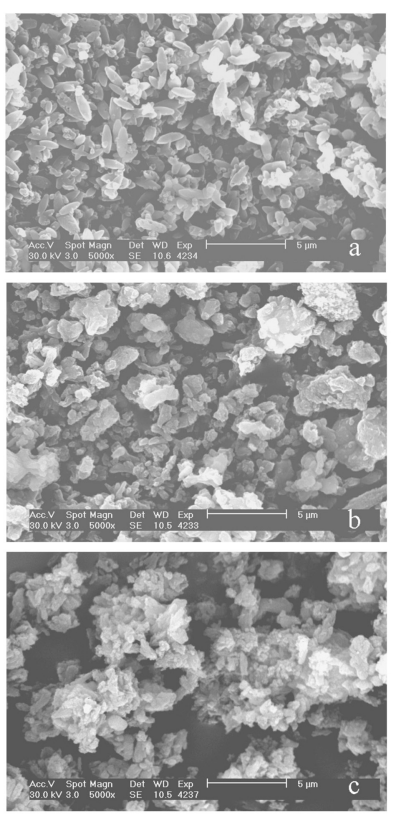

$\mathrm{B}$

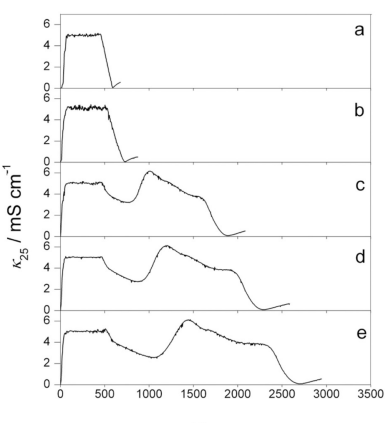

$t / \mathrm{s}$

C

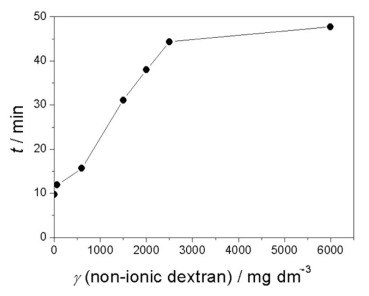

Figure 4. (A) Scanning electron micrographs of PCC samples isolated after completion the carbonation process performed at $35{ }^{\circ} \mathrm{C}$ and $\kappa_{25}=5.0 \mathrm{mS} \mathrm{cm}{ }^{-1}$ in the presence of different mass concentration of non-ionic dextran $\left(M_{\mathrm{r}}=150000 \mathrm{~g} \mathrm{~mol}^{-1}\right)$ : (a) 0 , (b) 1500 , (c) $2500 \mathrm{mg} \mathrm{dm}^{-3}$. (B) Progress curves of the carbonation processes at: (a) 0, (b) 60, (c) 1500 , (d) 2000 , (e) $2500 \mathrm{mg} \mathrm{dm}{ }^{-3}$ of non-ionic dextran. (C) Duration of the carbonation process as a function of mass concentration of non-ionic dextran in suspension.

Figure 4A shows SEM micrographs of the representative PCC samples obtained by the carbonation processes performed in the presence of different mass concentrations of the non-ionic dextran, $M_{\mathrm{r}}=150000 \mathrm{~g}$ $\mathrm{mol}^{-1}\left(60 \mathrm{mg} \mathrm{dm}^{-3}<\gamma<6000 \mathrm{mg} \mathrm{dm}^{-3}\right)$. The corresponding progress curves are represented in Figure $4 \mathrm{~B}$ together with the curve obtained in the model system, containing no dextran, which is shown for comparison. The micrographs indicate that the addition of non-ionic dextran influences the morphology and the size of PCC particles so that the typical scalenohedral crystals obtained in the model system at $\kappa_{25}=5.0 \mathrm{mS} \mathrm{cm}{ }^{-1}$ become aggregates of irregular crystallites with broad size distribution. This is evident even upon the addition of a small concentration of non-ionic dextran as $60 \mathrm{mg} \mathrm{dm}^{-3}$. The aggregation is intensified with the increase of nonionic dextran concentration, as well as the irregularity of the precipitate (Figure 4A). All this suggests a specific and coordinative interaction between the mineral surface and the dissolved additive.

The shape of the progress curve obtained in the system with the addition of the lowest concentration of non-ionic dextran $\left(\gamma=60 \mathrm{mg} \mathrm{dm}^{-3}\right.$, curve b) does not significantly differ from the shape of the curve corre- 


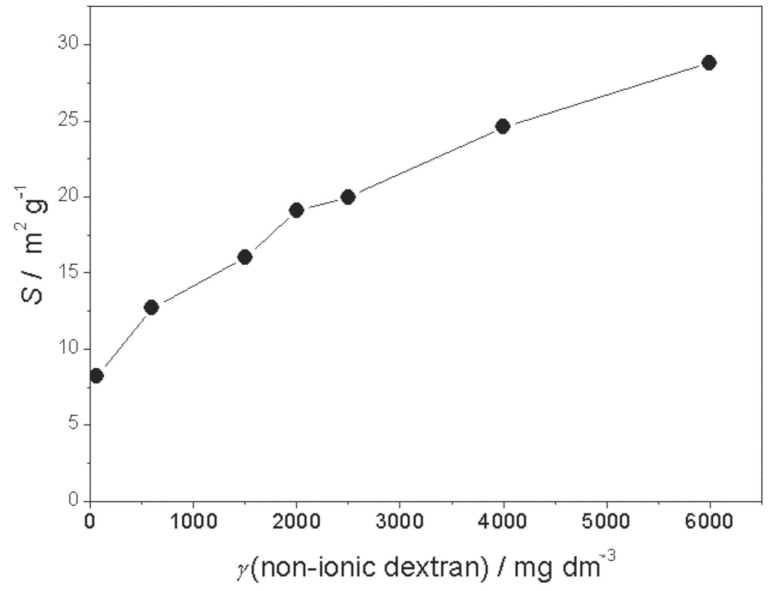

Figure 5. Plot of specific surface area, $S$, of $\mathrm{PCC}$ as a function of different concentrations of non-ionic dextran, $M_{\mathrm{r}}=150000$ $\mathrm{g} \mathrm{mol}^{-1}$. Experimental conditions: temperature $35^{\circ} \mathrm{C}, \kappa_{25}=5.0$ $\mathrm{mS} \mathrm{cm}{ }^{-1}$.

sponding to the model system (curve a). However, at higher concentrations of non-ionic dextran, the shape of the curves is significantly altered and the completion of the carbonation process significantly prolonged. Thus, after stopping the regulation of the process $(600 \mathrm{~s})$, the conductivity decreases relatively slowly to the value of about 2 to $3 \mathrm{mS} \mathrm{cm}^{-1}$ and increases afterwards to about $6 \mathrm{mS} \mathrm{cm}{ }^{-1}$. The subsequent slow decrease of conductivity is a consequence of conversion of the remaining $\mathrm{Ca}(\mathrm{OH})_{2}$ into PCC and completion of the carbonation process: it lasted almost 50 minutes at the highest concentration of dextran applied, in comparison to the approximately 11 minutes in the respective model system (Figure 4C).

Connected to the results mentioned above, the specific surface area of the precipitate increased by increasing the mass concentration of non-ionic dextran up to the highest value of $S=28.8 \mathrm{~m}^{2} \mathrm{~g}^{-1}$ when 6000 $\mathrm{mg} \mathrm{dm}{ }^{-3}$ of non-ionic dextran was added to the system. Figure 5 shows the relation between the non-ionic dextran concentration and the measured specific surface area of the PCC samples.

The observed appearance of the uncontrolled increase of conductivity (concentration) during the semicontinuous carbonation process in the systems containing no additives and at the temperatures lower than $30{ }^{\circ} \mathrm{C}$ has been previously described by the other authors. ${ }^{5,9,10}$ Such behaviour was assumed to be a consequence of the formation of an unstable precursor of the calcium carbonate phase, probably an amorphous calcium carbonate, on the surfaces of the suspended $\mathrm{Ca}(\mathrm{OH})_{2}$ particles. The unstable phase initially inhibits the dissolution of the solid $\mathrm{Ca}(\mathrm{OH})_{2}$, but due to its extreme instability, it rapidly dissolves, thus liberating the surface of $\mathrm{Ca}(\mathrm{OH})_{2}$ and causing the uncontrolled increase in conductivity. Similar mechanism was also found in a batch precipitation system at $35{ }^{\circ} \mathrm{C}$ in the presence of citrate, lignosulfonate and sucrose. ${ }^{32}$ However, a possible method to avoid the uncontrolled precipitation was proposed by Ukrainczyk et al.: ${ }^{10}$ by applying a very slow addition of $\mathrm{Ca}(\mathrm{OH})_{2}$ suspension at the beginning of the carbonation process, the accumulation of solid $\mathrm{Ca}(\mathrm{OH})_{2}$ can be prevented.

The additional parameter that probably influences the propagation of carbonatization process, which manifests as a change of shape of the progress curves, is the impact of dextran by the inhibition of ACC dissolution. It is known that ACC is transformed to more stable calcium carbonate modifications by a so-called solution mediated transformation, which comprises processes of simultaneous dissolution of ACC and nucleation and crystal growth of the more stable modifications, calcite or vaterite. ${ }^{33,34}$ However, in the presence of certain macromolecules, like natural glycoproteins and polysaccharides or synthetic polymers and even magnesium ions, ACC can be stabilized due to inhibition of its dissolution. ${ }^{35,36}$ Giles et al. $^{37}$ found that the dissolution of $\mathrm{Ca}(\mathrm{OH})_{2}$ at low stirring rate is controlled by the diffusion of calcium and hydroxide ions away from the surface, while the dissolution is surface controlled at an intensive stirring. Since it is generally accepted that polysaccharides adsorb on mineral surfaces through hydrogen bonds or chemical complexation process in which C-2, C-3 and C-6 hydroxyl groups play crucial roles, ${ }^{38-40}$ the inhibition of $\mathrm{Ca}(\mathrm{OH})_{2}$ dissolution is likely to occur. In other words, the presence of dextrane may cause progressive $\mathrm{Ca}(\mathrm{OH})_{2}$ accumulation in the systems containing higher concentrations of dextrans.

In order to explain the obtained shape of the progress curves, caused by the initial accumulation of solid $\mathrm{Ca}(\mathrm{OH})_{2}$, during the course of the carbonation process in the system containing $6000 \mathrm{mg} \mathrm{dm}^{-3}$ of non-ionic dextran, $M_{\mathrm{r}}=150000 \mathrm{~g} \mathrm{~mol}^{-1}$, the samples were removed from the precipitation system at different time intervals and analysed (see Figure 6). The separation time intervals are indicated by points 1 to 8 on the corresponding progress curve (Figure 6A) and a selection of FT-IR spectra of the representative solid phase samples are given in Figure 6B. Calcite in the samples was identified by the typical absorption bands, $v_{4}=713$ $\mathrm{cm}^{-1}$ and $v_{2}=876 \mathrm{~cm}^{-1}$, that are assigned as OCO bending (in-plane deformation) and $\mathrm{CO}_{3}$ out of plane deformation modes, respectively. ${ }^{41,42}$ The narrow band at $3642 \mathrm{~cm}^{-1}$ is attributed to the free stretching $\mathrm{O}-\mathrm{H}$ vibration and a broad band centred at $3400 \mathrm{~cm}^{-1}$ to the hydroxyl groups of $\mathrm{Ca}(\mathrm{OH})_{2}{ }^{43}$ The result of the semiquantitative estimate of the mineral phase content shows (Figure 6C) that during the initial part of the process (samples $1-3$ ), the solid $\mathrm{Ca}(\mathrm{OH})_{2}$ was accumulated in the system, while after stopping the regulation, the fraction of calcite increased as a consequence of $\mathrm{Ca}(\mathrm{OH})_{2}$ dissolution and simultaneous nucleation and 

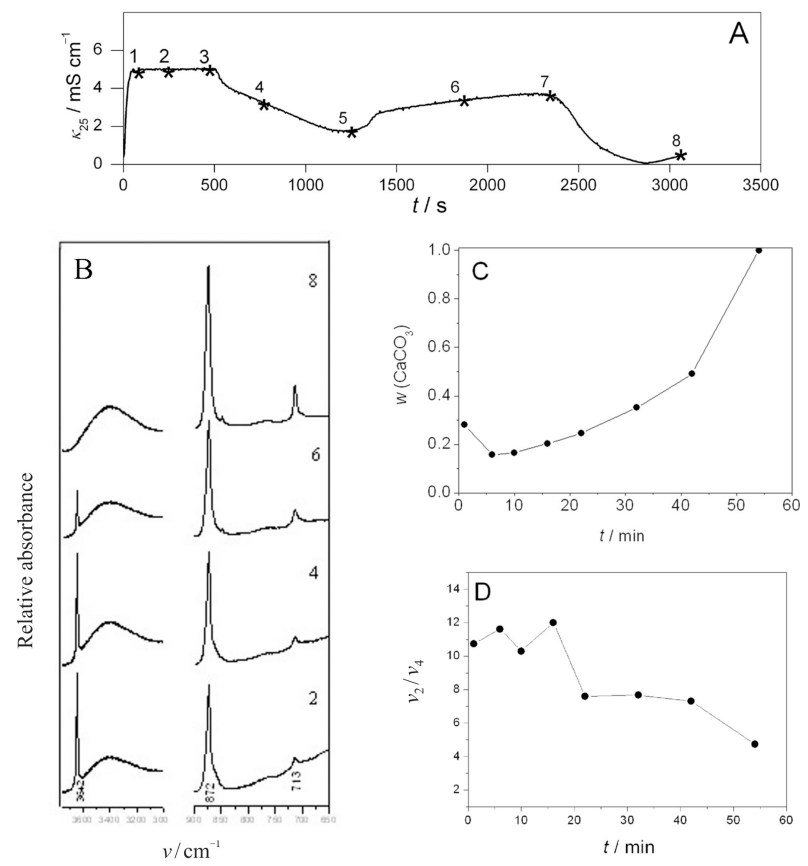

Figure 6. (A) Progress curve, $\kappa_{25}$ versus time, of the carbonation process at $35{ }^{\circ} \mathrm{C}$ and $\kappa_{25}=5.0 \mathrm{mS} \mathrm{cm}{ }^{-1}$ in the presence of $6000 \mathrm{mg} \mathrm{dm}^{-3}$ of non-ionic dextran $\left(M_{\mathrm{r}}=150000 \mathrm{~g} \mathrm{~mol}^{-1}\right)$. Points 1-8 correspond to the samples isolated at different times. (B) FT-IR spectra of samples isolated at time-points 2, 4, 6 and 8. (C) Calcite mass fractions, $w$, as a function of time corresponding to the samples 1-8. (D) The ratio of absorption bands, $v_{2} / v_{4}$ as a function of time for the samples 1-8.

growth of calcite. After termination of the carbonation process (sample 8 ) only calcite was observed in the system. It should be noted that the absorption bands of amorphous calcium carbonate ${ }^{3,27}$ at about 1490 and 1430 $\mathrm{cm}^{-1}\left(v_{3 \mathrm{a}}, v_{3 \mathrm{~b}}\right), 1080 \mathrm{~cm}^{-1}\left(v_{1}\right)$ and $866 \mathrm{~cm}^{-1}\left(v_{2}\right)$, as well as the extensively broadened bands at 725 and $690 \mathrm{~cm}^{-1}$ $\left(v_{4 \mathrm{a}}, v_{4 \mathrm{~b}}\right)$, can be hardly detected in the presence of large amounts of calcite. Instead, the hypothesized presence of this non-crystalline modification can be confirmed by comparing the ratios of the maximal intensities of $v_{2}$ and $v_{4}$ absorption bands: in the case of pure calcite the typical value of $v_{2} / v_{4}$ of about 3 is found, while in the mixtures containing ACC the ratio can substantially increase as a consequence of the absence of $v_{4}$ absorption of ACC in the $713 \mathrm{~cm}^{-1}$ region. ${ }^{35,44}$ Indeed, Figure $6 \mathrm{D}$ shows that the ratio of absorption bands at about $876 \mathrm{~cm}^{-1}$ and $713 \mathrm{~cm}^{-1}$ decrease with time and attains minimum in sample 8 .

The content of non-ionic dextran adsorbed on the surfaces of PCC samples and isolated at the end of carbonation process, was estimated by means of the thermogravimetric analysis. It was found that the decomposition of PCC samples, prepared in the presence of different mass concentrations of dextran (range from 60 to $6000 \mathrm{mg} \mathrm{dm}^{-3}$ ), occurred in two steps, opposite to the PCC samples prepared in the absence of additives. Fig-

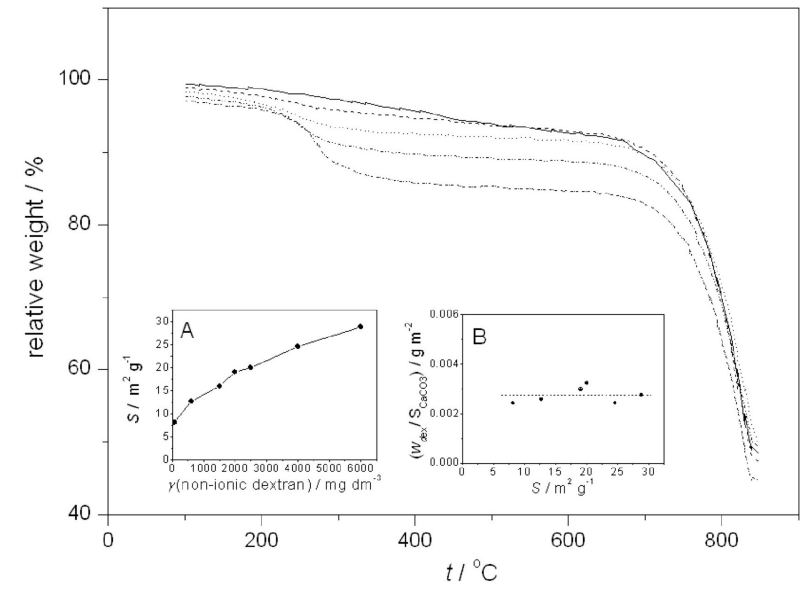

Figure 7. Thermogravimetric analysis of pure PCC samples (-) and PCC samples prepared in the presence of different mass concentration of non-ionic dextran $\left(M_{\mathrm{r}}=150000 \mathrm{~g}\right.$ $\left.\mathrm{mol}^{-1}\right)$ : 60 (----), 600 (…), $2500(-\cdots-. \cdot)$ and $6000 \mathrm{mg} \mathrm{dm}^{-3}$ (...-). Inset A: PCC specific surface area, $S$, as a function of different concentrations of non-ionic dextran. Inset B: standardized mass fraction of non-ionic dextran, $w_{\mathrm{dex}} / S_{\mathrm{CaCO} 3}$, as a function of PCC specific surface area, $S$.

ure 7 shows TGA curves of PCC samples prepared in the presence of different mass concentrations of nonionic dextran: the weight loss in the temperature range between 200 and $400{ }^{\circ} \mathrm{C}$ corresponds to the decomposition of dextran, while the decomposition of $\mathrm{CaCO}_{3}$ to $\mathrm{CaO}$ and $\mathrm{CO}_{2}$ occurs at about $800{ }^{\circ} \mathrm{C}$. It was found that the content of adsorbed dextran increased with increasing the addition of non-ionic dextran introduced in the precipitation system and the maximum value of the mass loss $(w=8 \%)$ was found for the system containing $6000 \mathrm{mg} \mathrm{dm}^{-3}$. However, when the mass loss of the adsorbed non-ionic dextran is standardized with respect to the surface area of respective PCC samples (inset in Figure 7$)$ the approximately constant value $\left(w_{\mathrm{dex}} / S_{\mathrm{CaCO} 3}\right.$ $\approx 0.003 \mathrm{~g} \mathrm{~m}^{-2}$ ) was found.

The effect of the addition of anionic dextran (dextran sulfate) on the physical properties of PCC prepared by semicontinuous carbonation process was also investigated. Somewhat surprisingly, it was found that dextran sulfate does not significantly influence the carbonation process, i.e. the process was fully controlled at any predetermined value of calcium concentration, even at the highest concentration of anionic dextran addition. Besides, the morphology of thus obtained calcite was apparently identical to calcite prepared in the model system: PCC appeared in the form of scalenohedral crystals and average particle size was found to be in the range from 0.5 to $2 \mu \mathrm{m}$. The only difference to the model system was a somewhat larger specific surface area, $S \approx 7 \mathrm{~m}^{2} \mathrm{~g}^{-1}$.

The results indicated that interactions between the positively charged mineral surface, as determined by 
acustophoretic measurements, ${ }^{45,46}$ and the negatively charged dextran sulfate molecules are most probably electrostatical and non-specific, in contrast to the more specific and coordinative interactions between the surface calcium ions and oxygen from the hydroxyl groups of non-ionic dextrans. Similar electrostatic interactions of calcite were obtained also previously. ${ }^{47}$ Thus, the specific and strong coordinative interactions were found between the negatively charged calcite surfaces and oxygen from the carboxyl groups of poly-L-aspartic or poly-L-glutamic acid, opposite to the weak, electrostatic and non-specific interactions of negatively charged calcite and positively charged poly-L-lysine.

\section{CONCLUSION}

The precipitation of calcium carbonate performed in semicontinuous carbonation process at 35 and $45{ }^{\circ} \mathrm{C}$ resulted in the formation of rhombohedral calcite crystals at $\kappa_{25} \leq 1.0 \mathrm{mS} \mathrm{cm}^{-1}\left(c(\mathrm{Ca})_{\text {tot }} \leq 2.4 \mathrm{mmol} \mathrm{dm}^{-3}\right)$ and rhombohedral or rhombo-scalenohedral crystals at $\kappa_{25}>$ $1.0 \mathrm{mS} \mathrm{cm}{ }^{-1}\left(c(\mathrm{Ca})_{\text {tot }}>2.4 \mathrm{mmol} \mathrm{dm}^{-3}\right)$. Predominantly scalenohedral crystals were prepared at $35{ }^{\circ} \mathrm{C}$ and $\kappa_{25}=$ $5.0 \mathrm{mS} \mathrm{cm}{ }^{-1}\left(c(\mathrm{Ca})_{\text {tot }}=12 \mathrm{mmol} \mathrm{dm}{ }^{-3}\right)$. The specific surface area of PCC increased with increasing the concentration of $\mathrm{Ca}(\mathrm{OH})_{2}$ and the maximum value was found to be about $6 \mathrm{~m}^{2} \mathrm{~g}^{-1}$.

The addition of non-ionic dextran strongly influenced the carbonation process and caused an uncontrolled increase of dissolved calcium concentration. A probable reason for such a behaviour was the inhibition of $\mathrm{Ca}(\mathrm{OH})_{2}$ dissolution and the inhibition of amorphous calcium carbonate dissolution that was initially formed at the surfaces of $\mathrm{Ca}(\mathrm{OH})_{2}$. The inhibition was caused by adsorption of dextran molecules on the mineral surfaces. The morphology and specific surface area of thus prepared PCC were also influenced and the irregular crystal aggregates of relatively high specific surface area, $S \approx 29 \mathrm{~m}^{2} \mathrm{~g}^{-1}$ were obtained.

The anionic dextran did not significantly influence the carbonation process as well as the physical properties of calcite crystals.

Acknowledgements. The authors thank to dr. sc. Ljerka Brečević for useful suggestions and reading the manuscript. The financial support from the Ministry of Science, Education and Sports of the Republic of Croatia (project No. 098-0982904$2951)$ is gratefully acknowledged.

\section{REFERENCES}

1. M. Kitamura, J. Cryst. Growth 237-239 (2002) 2205-2214.

2. W. S. Kim, I. Hirasawa, and W. S. Kim, Ind. Eng. Chem. Res. 43 (2004) 2650-2657.

3. K. Uebo, R. Yamazaki, and K. Yoshida, Adv. Powder Technol. 3 (1992) 71-79.
4. L. Xiang, Y. Xiang, Y. Wen, and F. Wei, Mater. Lett. 58 (2004) 959-965.

5. J. Garcia-Carmona, J. Gomez-Morales, and R. RodrigrezClemente, J. Colloid Interface Sci. 261 (2003) 434-440.

6. S. Y. Park and W. S. Choi, Adv. Powder Technol. 15 (2004) $1-12$.

7. D. Gomez-Diaz, J. M. Navaza, and B. Sanjurjo, Chem. Eng. J. 116 (2006) 203-209.

8. B. Feng, A. K. Yong, and H. An, Mater. Sci. Eng. A 445-446 (2007) 170-179.

9. J. Garcia-Carmona, J. Gomez-Morales, and R. RodrigrezClemente, J. Cryst. Growth 249 (2003) 561-571.

10. M. Ukrainczyk, J. Kontrec, V. Babić-Ivančić, Lj. Brečević, and D. Kralj, Powder Technol. 171 (2007) 192-199.

11. M. Ukrainczyk, J. Kontrec, V. Babić-Ivančić, Lj. Brečević, and D. Kralj, Kem. Ind. 56 (7-8) (2007) 385-390.

12. A. Fathi, T. Mohamed, G. Claude, G. Maurin, and B. A. Mohamed, Water Res. 40 (2006) 1941-1950.

13. E. Chibowski, L. Holysz, A. Szczes, and M. Chibowski, Colloids Surf., A 225 (2003) 63-73.

14. C. Domingo, E. Loste, J. Gomez-Morales, J. Garcia-Carmona, and J. Fraile, J. Supercrit. Fluids 36 (2005) 202-215.

15. G. Montes-Hernandeza, F. Renarda, N. Geoffroya, L. Charleta, and J. Pirononb, J. Cryst. Growth 308 (2007) 228-236.

16. L. Pach, S. Duncan, R. Roy, and S. Komarneni, J. Mater. Sci. 31 (1996) 6565-6569.

17. V. V. Hardikar and E. Matijević, Colloids Surf., A 186 (2001) 23-31.

18. D. Kralj, J. Kontrec, Lj. Brečević, G. Falini, and V. NoethigLaslo, Chem. -Eur. J. 10 (2004) 1647-1656.

19. J. Kontrec, D. Kralj, Lj. Brečević, G. Falini, S. Fermani, V. Noethig-Laslo, and K. Mirosavljević, Eur. J. Inorg. Chem. 23 (2004) 4597-4585.

20. J. G. Yu, M. Lei, B. Cheng, and X. Zhao, J. Cryst. Growth 261 (2004) 566-570.

21. Y. Sheng, B. Zhou, J. Zhao, N. Tao, K. Yu, Y. Tian, and Z. Wang, J. Colloid Interface Sci. 272 (2004) 326-329.

22. M. Ukrainczyk, J. Kontrec, and D. Kralj, J. Colloid Interface Sci. 329 (2008) 89-96.

23. A. Gibbs, R. Pelton, and R. Cong, Colloids Surf., A 159 (1999) 31-45.

24. T. Smith-Palmer and R. Pelton, Colloids Surf., A 181 (2001) 171-181.

25. J. Wang and P. Somasundaran, J. Colloid Interface Sci. 309 (2007) 373-383.

26. R. Subramanian, H. Fordsmand, and H. Paulapuro, BioResources 2(1) (2007) 91-105.

27. R. Nyström, G. Hedström, J. Gustafsson, and B. Rosenholm, Colloids Surf., A 234 (2004) 85-93.

28. L. Yang, X. Zhang, Z. Liao, Y. Guo, Z. Hu, and Y. Cao, J. Inorg. Biochem. 97 (2003) 377-383.

29. R. Nyström, G. Hedström, J. Gustafsson, and B. Rosenholm, Colloids Surf., A 234 (2004) 85-93.

30. J. Kontrec, D. Kralj, Lj. Brečević, and G. Falini, J. Cryst. Growth 310 (2008) 4554-4560.

31. E. Ruiz-Agudo, C. V. Putnis, C. Rodriguez-Navarro, and A. Putnis, Geochim. Cosmochim. Acta 75 (2011) 284-296.

32. J. Garcia-Carmona, J. Gomez-Morales, J. Fraile-Sainz, and R. Rodrigrez-Clemente, Powder Technol. 130 (2003) 307-315.

33. D. Kralj, Lj. Brečević, and J. Kontrec, J. Cryst. Growth 177 (1997) 248-257.

34. B. Njegić-Džakula, G. Falini, Lj. Brečević, Ž. Skoko, and D. Kralj, J. Colloid Interface Sci. 343 (2010) 553-563.

35. S. Raz, P. S. Hamilton, F. H. Wilt, S. Weiner, and L. Addadi, Adv. Funct. Mater. 13 (2003) 480-486.

36. S-C. Huang, K. Naka, and Y. Chujo, Langmuir 23 (2007) 12086-12095. 
37. D. E. Giles, I. M. Ritchie, and B.-A. Xu, Hydrometallurgy 32 (1993) 119-128.

38. Q. Liu, Y. Zhang, and J. S. Laskowski, Int. J. Miner. Process. 60 (2000) 229-245

39. G. B. Raju, A. Holmgren, and W. Forsling, J. Colloid Interface Sci. 193 (1997) 215-222.

40. G. B. Raju, A. Holmgren, and W. Forsling, J. Colloid Interface Sci. 200 (1998) 1-6.

41. F. A. Andersen and D. Kralj, Appl. Spectrosc. 45 (1991) $1748-1751$.

42. F. A. Andersen and Lj. Brečević, Acta Chem. Scand. 45 (1991)
1018-1024.

43. M. J. Blesa, J. L. Miranda, and R. Moliner, Vib. Spectrosc. 33 (2003) 31-35.

44. E. Beniash, J. Aizenberg, L. Addadi, and S. Weiner, Proc. R. Soc. Lond. B 264 (1997) 461-465.

45. R. Eriksson, J. Merta, and J. B. Rosenholm, J. Colloid Interface Sci. 313 (2007) 184-193.

46. P. Virtanen (2003) Precipitated calcium carbonate and method for the production thereof. US Patent 6,602,484 B1.

47. B. Njegić-Džakula, Lj. Brečević, G. Falini, and D. Kralj, Cryst. Growth Des. 9 (2009), 2425-2434. 